\title{
Genetic cargo in the population of Kazakhstan according to the information- analytical system «Umit»
}

\section{Gulshara Abildinova $^{1}$, Dina Zhanatayeva ${ }^{1}$, Almagul Nagymtayeva ${ }^{1}$}

${ }^{1}$ Corporate Foundation "University Medical Center", National Scientific Center for Maternity and Childhood, Department of Clinical and Genetic Diagnostics, Astana, Kazakhstan

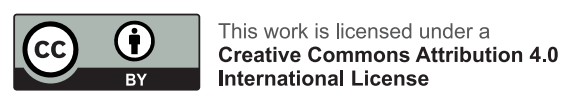

\section{УДК 616.00:616.013}

\section{J CLIN MED KAZ 2017; 3(45 SUPPL 3):51-54}

Corresponding author: GulsharaAbildinova, Corporate Foundation "University Medical Center", National Scientific Center for Maternity and Childhood, Department of Clinical and Genetic Diagnostics. Address: 010000, Astana, Kazakhstan. Phone: +7(7172)70-44-64.E-mail: labgen-astana@mail.ru

\section{ABSTRACT}

Purpose: to study of the frequency and structure of congenital and hereditary pathology according to the information-analytical database of congenital malformations and hereditary diseases.

Methods: pregnant at risk groups, newborns, children, adults and families with isolated and multiple developmental defects, hereditary metabolic disorders, as well as couples suffering from infertility and miscarriage. The diagnosis was verified using modern genetic methods (G-banding, FISH-method, RFLP, MLPA, mass spectrometric and fluorimetric, cytogenetic methods).

Results: according to the data of the genetic register, 36\% (1446) of strict accounting were prevailing in the structure of pathologies, chromosome pathology-28\% (1129), aneuploidy prevailed 97\% (1013), 22\% (869) of monogenic pathology with autosomal recessive type inheritance was 52\% (456), autosomal dominant inheritance type 32\% (283), X-linked inheritance type 26\% (130). In addition, the congenital and hereditary pathology in the prenatal period is recorded; the share was $16 \%(630)$. In the structure of prenatal and postnatal pathology, Down syndrome predominated $62.7 \%$ (625).

Conclusion: Thus, the formation of a database of congenital and hereditary pathologies with full coverage of all newborns, children, fetuses, comprehensive examination of families and clarification of the diagnosis, allows establishing the frequency, structure of congenital malformations and hereditary pathology.

Key words: congenital malformations, monogenic pathology, chromosomal pathology, register.

\section{ҚАЗАҚСТАНПОПУЛЯЦИЯСЫНДАГЕНЕТИКАЛЫҚПАТОЛОГИЯНЫНТАРАЛУЫ. «UМІТ» АҚПАРАТТЫҚ-ТАЛДАУ ЖУЙЕСІНІН МӘЛІМЕТЕРІ БОЙЫНША}

ӘбілдиноваГ.Ж. ${ }^{1}$ ЖанатаеваД.Ж. ${ }^{1}$, НагимтаеваА.А. ${ }^{1}$

${ }_{1}^{1}$ «University Medical Center» корпоративті фонды, Ана мен бала ұлттық ғылыми орталығы, клиника-генетикалық зерттеу бөлімше, Астана, Қазақстан

\section{ТҮЙІНДЕМЕ}

Зерттеудің мақсаты: туа біткен кемістіктер және тұқым қуалайтын аурулардың ақпараттық-талдамалық базасына сәйкес туа біткен және тұқым қуалайтын патологияның жиілігі мен құрылымын зерттеу.

Әдістері: қауіп-қатері бар жүкті әйелдер, жаңа туған нәрестелер, балалар, ересек адамдар және оқшауланған мен көптеген даму ақаулары бар, зат алмасудың тұқым қуалайтын өзгерістері бар отбасы, бедеулік пен жүктіліктің соңына дейін жетпеуімен қиналатын ерлізайыптылар. Диагноздың аңықталуы жаңа генетикалық әдістердің қолдануымен жасалған (G-бандинг, FISH - әдіс, ПДРФ, MЛРА, массспектрометрикалық және фрлуориметрикалық, цитогенетикалық әдістер).

Нәтижесі: генетикалық регистр бойынша аурулардың құрамында ақаулар басым болды 36\% (1446), хромосомдық патология - 28\% (1129), олардың ішінен анеуплоидиялар 97\% (1013), моногендік патологияның үлесі - 22\%(869), олардың ішінен аутосом-рецессивтік тұқымқуалау түрі 52\%(456) тұрады, аутосом-доминанттық тұқымқуалау түрі - 32\% (283), Х-тіркелген тұқымқуалау түрі 26\% (130).

Тағы да, пренаталдық кезенінде туа біткен және тұқымқуалау аурулардың есебі жүреді, оның үлесі 16\% (630) құрайды. Пренаталдық және постнаталдық ауруларадың ішінде Даун синдромы басым алған - 62,7\% (625).

Қорытынды: Сонымен, туа біткен және тұқымқуалау аурулары бар бүкіл жаңа туған нәрестелер, балалар, ұрықтар, комплекстік тексеруден өткен және диагнозы анықталған отбасылар туралы акпараттық базаның қалыптастыруы, туа біткен кемістіктер және тұқымқуалау аурулардың жиілігін, құрамын анықтауға мүмкіндік береді.

Түйінді сөздер: туа біткен кемістіктер, моногендік патология, хромосомдық патология, регистр. 
РАСПРОСТРАНЕННОСТЬ ГЕНЕТИЧЕСКОЙ ПАТОЛОГИИ В ПОПУЛЯЦИИ КАЗАХСТАНАПО ДАННЫМ ИНФОРМАЦИОННО-АНАЛИТИЧЕСКОЙ СИСТЕМЫ «UМІТ»

Абильдинова Г.Ж ${ }^{1}$., Жанатаева Д.Ж ${ }^{1}$., Нагимтаева А.А. ${ }^{1}$

${ }^{1}$ Корпоративный фонд «UniversityMedicalCenter», Национальный научный центр материнства и детства,отделение клинико-генетической диагностики, Астана, Казахстан

PEЗЮME

Цель:изучение частоты и структуры врожденной и наследственной патологии по данным информационно-аналитической базы ВПР и наследственных заболеваний.

Материалы и методы: беременные группы риска, новорожденные, дети, взрослые и семья с изолированными и множественными пороками развития, наследственными нарушениями обмена веществ, а также супружеские пары, страдающих бесплодием и невынашиванием беременности. Верификация диагноза была проведена с применением современных генетических методов (G - бандинг, FISH - метод, ПДРФ, МЛРА, масс-спектрометрические и фрлуориметрические, цитогенетические методы).

Результаты: по данным генетического регистра в структуре патологий преобладали пороки строгого учета $36 \%$ (1446), хромосомная патология-28\% (1129), из них преобладали анеуплоидии 97\% (1013), доля моногенной патологии составило 22\%(869), из которых с аутосомно-рецессивным типом наследованием составила 52\%(456), аутосомно-доминантный тип наследования 32\% (283), Х-сцепленный тип наследования 26\% (130).А также, ведется учет врожденной и наследственной патологии в пренатальном периоде, доля которого составила $16 \%$ (630). В структуре пренатальной и постнатальной патологии преобладал синдром Дауна $62,7 \%$ (625).

Выводы: Таким образом, формирование базы данных врожденной и наследственной патологии с полным охватом всех новорожденных, детей, плодов, комплексного обследования семей и уточнения диагноза, позволяет установить частоту, структуру ВПР и наследственной патологии.

Ключевые слова: врожденные пороки развития, моногенная патология, хромосомная патология, регистр.

\section{Выводы}

В настоящее время одной из серьезной медикосоциальных проблем являются врожденные и наследственные заболевания (ВН3) у детей, которые в течение последнего десятилетия удерживают лидирующие позиции в структуре причин перинатальной, неонатальной, младенческой заболеваемости, инвалидности и смертности [1]. По данным Всемирной организации здравоохранения (BO3), в настоящее время более 5000 болезней вызваны генетическими нарушениями. Так, 5-8\% новорождённых появляются на свет с врождёнными дефектами, 40\% ранней детской смертности и $50 \%$ выкидышей обусловлены генетической патологией. В структуре заболеваемости и смертности на долю врожденных пороков развития (ВПР) приходится 20,4\%. В возрасте до одного года умирают более $20 \%$ детей с врожденными пороками развития, оставшиеся в живых, в большинстве случаев, являются умственно или физически неполноценными. В тоже время, в различных источниках данные о частоте ВПР противоречивы, и частота колеблется от 4,3 до 55 на 1000 новорожденных (у $15 \%$ детей - пороки несовместимые с жизнью, а у 25\% приводят к ранней неонатальной смертности) [1].

Так, в Республике Казахстан ежегодно рождается более трех тысячдетей с врожденными и наследственными заболеваниями, что составляет от 20,0 до 24,3 на каждую тысячу новорожденных. Удельный вес врожденных пороков развития в структуре перинатальной смертности составляет $30-40 \%$, занимая второе - третье место [1].

Существующий в РеспубликеКазахстан Национальный Генетический регистр, включает данные о частоте ВПР, который учитывает врожденные пороки развития строгого учета только у новорожденных в первые 7 суток жизни. Следует отметить, в неонатальном периоде фиксируются в основном лишь грубые аномалии развития, определяемые adoculus, т.е. те, которые не зависят от квалификации медицинского персонала и не возможно их не увидеть. Однако, статистика, основанная на определении только частоты ВПР у новорожденных не отражает существующую действительность, так как невидимые пороки развития различных органов и систем, моногенная и хромосомная патология диагностируются у выживших детей лишь спустя месяцы и годы[1,2].

Одним из критериев оценки отягощенности популяции генетической патологией являетсяразработка единой системы мониторинга ВПР, которая позволит не только оценить частоту ВПР в популяции, но и предоставит возможность для изучения их эпидемиологических характеристик.

На базе лаборатории клинико - генетической диагностики разработана программа регистрации и учета врожденной и наследственной патологии «Umit» на основе унифицированных методов регистрации всего спектра врожденной и наследственной патологии, с полным охватом всех новорожденных и детей, умерших от врожденных или наследственных заболеваний, комплексного обследования семей и уточнения диагноза.

Цель: изучение частоты и структуры врожденной и наследственной патологии по данным информационноаналитической базы ВПР и наследственных заболеваний.

\section{Материалы и методы исследования}

База данных формировалась на основе медикогенетического консультирования беременных группы риска, новорожденных, детей и взрослых с изолированными и множественными пороками развития, наследственными нарушениями обмена веществ, семей с наследственной и врожденной патологиями, а также супружеских пар, страдающих бесплодием и невынашиванием беременности.

Регистрация врожденной и наследственной патологии проводилась по нозологическим формам в соответствии с Международной классификации болезней (X пересмотр, XVII класс «Врожденные аномалии, деформации и хромосомные нарушения»), а также с учетом перечня ВПР - 21-й нозологической формы, подлежащих обязательной регистрации в соответствии с международными системами EUROCAT, что позволяет сопоставить и интегрировать результаты с данными международных регистров[3,4].

\section{Результаты}

На сегодняшний деньв базе данных генетического регистра зарегистрировано более 4000 случаев с врожденной и наследственной патологией, из них в 13\% - в пренатальном периоде. В структуре преобладали ВПР - 2002 (50\%), из них около 50\% ВПР строго учета, хромосомная патология выявлена в 1129 (28\%) случаях, моногенная у 869 пациентов (22\%). Результаты представлены в таблице 1. 
Таблица 1 Структура врожденной и наследственной патологии

\begin{tabular}{|l|l|l|l|l|}
\hline № & & Наименование & Количество & Доля \\
\hline 1 & $\begin{array}{l}\text { Врожденные пороки } \\
\text { развития }\end{array}$ & 2002 & $50 \%$ & \\
\hline 2 & $\begin{array}{l}\text { Хромосомная } \\
\text { патология }\end{array}$ & 1129 & $28 \%$ & \\
\hline 3 & $\begin{array}{l}\text { Моногенная } \\
\text { патология }\end{array}$ & 869 & $22 \%$ & \\
\hline
\end{tabular}

При анализе всех форм ВПР получено, что наибольший удельный вес приходится на пороки развития системы кровообращения - 698 (34,8\%),наиболее часто в группе аномалий встречались дефект межжелудочковой перегородки, дефект межпредсердной перегородки, тетрадо Фалло и транспозиция сосудов. ВПР мочевыделительной системы обнаружены у 203 (10,1\%) пациентов, чаще всего выявлены обструктивные уропатии, гидронефроз почек, мультикистозная трансформация почек. ВПР органов пищеварения выявлены у 285 (14,3\%) пациентов, ВПР нервной системы у 242 (13,1\%), костно - мышечной системы - 131 (5,3\%), ВПР лицевых структур в 125 (4,6\%) случаях (Таблица 2).

Таблица 2 Структура врожденных пороков развития

\begin{tabular}{|l|l|l|l|}
\hline \multirow{2}{*}{$\begin{array}{l}\text { № } \\
\text { п/п }\end{array}$} & ВПР & \multicolumn{2}{|l|}{ Количество } \\
\cline { 3 - 4 } & & $\begin{array}{l}\text { Абсолютное } \\
\text { число }\end{array}$ & $\begin{array}{l}\text { Доля порока от } \\
\text { общего числа } \\
\text { ВПР, \% }\end{array}$ \\
\hline I & МВПР & 230 & $11,4 \%$ \\
\hline II & Изолированные ВПР: & 1772 & $88,6 \%$ \\
\hline 1 & ВПР системы кровообращения & 698 & $34,8 \%$ \\
\hline 2 & ВПР мочевыделительной системы & 203 & $10,1 \%$ \\
\hline 3 & ВПР органов пищеварения & 285 & $14,3 \%$ \\
\hline 4 & ВПР нервной системы & 242 & $13,1 \%$ \\
\hline 5 & Костно - мышечной системы & 131 & $5,3 \%$ \\
\hline 6 & ВПР лицевых структур & 125 & $4,6 \%$ \\
\hline 7 & Другие & 88 & $6,7 \%$ \\
\hline & Итого & & $100 \%$ \\
\hline & & & \\
\hline
\end{tabular}

В таблице 3 представлены результаты частота и структура хромосомной патологи. Диагноз был подтвержден цитогенетическими (G - бандинг) и молекулярноцитогенетическими исследованиями (FISH - метод). В общее число хромосомных аномалий входила патология, диагностированная в ходе пренатального и постнатального кариотипирования (751- постнатально, 372 - пренатально).

Таблица 3 Хромосомная патология

\begin{tabular}{|l|l|l|l|}
\hline \multirow{2}{*}{$\begin{array}{l}\text { № } \\
\text { n/п }\end{array}$} & Хромосомная аномалия & Количество & \multicolumn{2}{|l|}{} \\
\cline { 3 - 4 } & & $\begin{array}{l}\text { Абсолютное } \\
\text { число }\end{array}$ & $\begin{array}{l}\text { Доля отдельных } \\
\text { синдромов от } \\
\text { общего числа } \\
\text { ХА, \% }\end{array}$ \\
\hline 1 & Синдром Дауна & 625 & $62,7 \%$ \\
\hline 2 & Синдром Эдвардса & 182 & $16,2 \%$ \\
\hline 3 & $\begin{array}{l}\text { Синдром Шерешевского - } \\
\text { Тернера }\end{array}$ & 88 & $7,8 \%$ \\
\hline 4 & Синдром Клайнфелтера & 67 & $5,9 \%$ \\
\hline 5 & Синдром Патау & 51 & $4,5 \%$ \\
\hline 6 & Трисомии по Х -хромосоме & 33 & $2,9 \%$ \\
\hline & Итого & 1123 & 100 \\
\hline
\end{tabular}

При цитогенетическом исследовании наиболее чаще диагностировали синдром Дауна - 625 (62,7\%), на втором месте по частоте занимает синдром Эдвардса- 182 (16,2\%), синдром Шерешевского - Тернера - 88 (7,8\%)случаях, Синдром Клайнфелтера - 67 (5,9\%), синдром Патау - 51 (4,5\%).

Моногенная патология была выявлена в 869 (22\%) случаях.Материалы таблицы показывают, что среди моногенной патологии чаще диагностировался аутосомнорецессивный тип наследования (спинальная мышечная амиотрофия, фенилкетонурия, муковисцидоз), на их долю приходится 52\% от всей моногенной патологии.

\section{Таблица 4 Моногенная патология}

\begin{tabular}{|l|l|l|}
\hline Моногенная патология & \multicolumn{2}{|l|}{ Количество } \\
\cline { 2 - 3 } & Абсолютное число & $\begin{array}{l}\text { Доля отдельных синдромов } \\
\text { от общего числа (\%) }\end{array}$ \\
\hline $\begin{array}{l}\text { Аутосомно-доминантный } \\
\text { тип наследования }\end{array}$ & 283 & $32 \%$ \\
\hline $\begin{array}{l}\text { Аутосомно-рецессивный } \\
\text { тип наследования }\end{array}$ & 456 & $52 \%$ \\
\hline Х-сцепленный & 130 & $26 \%$ \\
\hline
\end{tabular}

Кроме того, в регистре имеется информация о 74 пациентов с орфанными заболеваниями, в частности с мукополисахаридозом 1, 2, 4 и 6 типов. Верификация диагнозов проводилась с применением современных генетических методов (ПДРФ, МЛРА, массспектрометрические и флуориметрические методы).

\section{Обсуждение}

На международном уровне регистры представлены двумя системами: Clearinghouse и EUROCAT. Стандартизированная система Европейского международного регистра EUROCAT включает 19 форм ВПР и Clearinghouse - данные о 21 клинически диагностируемых ВПР у новорожденных. В тоже время в мире активно разрабатываются регистры, в которых помимо пороков строго учета учитываются пороки так называемые «малые» пороки развития, которые не приводят к существенным функциональным нарушениям. Исключение «малых» пороков из системы динамического наблюдения или их «недоучет» может привести к пропуску части МВПР (синдромов), которые могут быть выявлены в результате цитогенетического, ультразвукового исследования.В разработанном регистре «Umit» помимо учета 21 формы пороков строго учета, регистрируется весь спектр ВПР, моногенная и хромосомная патология, что показывает уникальность разработанной системы.

По результатам проведенных исследований базе «Umit», в сравнении с данными EUROCAT чаще встречаются синдром Дауна, множественные врожденные пороки развития, врожденные пороки сердца (ВПС), a также такие пороки развития, как гидроцефалия, диафрагмальная грыжа, Spinabifida. Данные пороки развития входят в группу изолированных ВПР, в этиологии которых преобладает мультифакториальная компонента. При сравнении частоты ВПР в регистре «Umit» с аналогичными показателями в EUROCAT было выявлено, что распространенность ряда пороков центральной нервной системы (анэнцефалия,энцефалоцеле), а также микротий, агенезий почек и экстрофий мочевого пузыря в 2-3 раза ниже. 
Частота отдельных нозологических форм ВПР в «Umit» при сопоставлении с данными, полученными в исследованиях Федерального регистра, также имеет свои особенности. В Федеральном регистре несколько выше частота гипоспадии, синдрома Дауна, редукционных пороков конечностей множественных врожденных пороков, а частота агенезии и дисгенезии почек, микрофтальмии и ВПС - ниже.

Такие виды врожденных пороков, как микрофтальмия и анофтальмия, встречаются в нашем регионе в 3 раза реже, чем по данным, зафиксированным Европейским регистром. Частота гипоспадии в регистре «Umit», выше величины колебания частоты данной формы патологии, при вводимой в регистре EUROCAT. При сравнении частоты BПР в «Umit» с аналогичными показателями в Федеральном регистре, было выявлено, что распространенность ряда пороков центральной нервной системы (спинномозговая грыжа, врожденные пороки сердца, гидроцефалия, расщелины губы и нёба), а также атрезий ануса и пищевода, среди зарегистрированных в нашей базе данных 2-3 раза выше. Ведущими или базовыми в структуре ВПР по данным регистра«Umit» являются синдром Дауна и множественные пороки развития. В структуре множественных врожденных пороков доля доминантных, хромосомных и сцепленных с полом заболеваний достаточно высока, а мутационная компонента составляет не менее $40 \%$. И напротив, такой патологии, как, полидактилия, гастрошизис, энцефалоцеле, анэнцефалия агенезий почек и омфалоцеле - на порядок ниже, чем в Федеральном регистре РФ.

Анализ дополнительных факторов риска, информация о которых получена при обследовании показал, что беременность чаще протекала с осложнениями I половины, в виде угрозы прерывания и гестоза. С высокой степенью достоверности было показано, что у родителей детей с ВПР чаще регистрировалась хроническая патология, вредных привычек и ВПР.
Нозологический спектр наследственных заболеваний показывает, что в республике среди моногенной патологии преобладают заболевания с АР типом наследования, что вероятно объясняется носительством патологичных генов. Следует отметить, что боль-шинство из зарегистрированных $\mathrm{AP}$ заболеваний характерны и для российских и европейских популяций. Впервые нам встретились патологии как:

синдром Криста-Сименса-Турена (ОМІМ №305100); синдром Ларсена (ОМIM №150250), синдром Секкеля (OMIM №210600).По данным международного регистра EUROCAT, встречаемость этих синдромов составляет 1-3\%. Остальные наследственные заболевания с АР типом наследования встретились с распространенностью менее 1:50 000 и в основном выявлены в единичных случаях[8,9].

В структуре хромосомной патологии преобладали анеуплоидии, преимущественно синдром Дауна 63\% (625). Высокий процент синдрома в популяции объясняется мутациями в яйцеклетках и предрасположенность к анеуплоидиям[6,7].

Создание регионального генетического регистра на основе унифицированных методов регистрации всего спектра ВПР, с полным охватом всех новорожденных и детей, умерших от врожденных или наследственных заболеваний, комплексного обследования семей и уточнения диагноза, длительного хранения информации и возможности ее извлечения для анализа способствует созданию динамичной системы реагирования на формирование генетического груза в Республике Казахстан.

\section{Выводы}

В структуре патологий в казахской популяций преобладают врожденные пороки развития (50\%), в структуре хромосомной патологий - анеуплоидии (97\%), в структуре моногенной патологии - заболевания с аутосомнорецессивным типом наследования (52\%).

\section{Литература}

1. BarashnevJuI, Baharev VA. Jembriofetopatii. Diagnostika i profilaktika anomalij central'noj nervnoj sistemy i skeleta(Embryophytopathy. Diagnosis and prevention of anomalies of the central nervous system and skeleton) [in Russian]. M.: Triada $-X, 2010$.

2. Demikova NS. Informacionno-spravochnaja sistema povrozhdennym porokam razvitija $\mathrm{v}$ medicinskoj praktike i obrazovanii(Information-reference system on congenital malformations in medical practice and education) [in Russian]. Vrachi informacionnye tehnologii. 2007; 6: 33-36.

3. Dolk H. Arch. Dis. EUROCAT: 25 years of European surveillance of congenital anomalies. Child Fetal Neonatal. Edition. 2005; 90: 355-358.

4. EUROCAT. Instructions for the Registration and Surveillance of Congenital Anomalies. 2005. WEB: http: // www.eurocat.ulster. ac.uk /

5. Greenlees R, Neville A, Addor MC, Amar E, Arriola L, Bakker M. et al. Paper 6: EUROCAT member registries: organization and activities. Birth defects research Part A, Clinical and molecular teratology. 2011;91(Suppl 1):51-100.

6. Baranov VS, Kuznecova TV. Citogenetikaj embrional'nogo razvitija cheloveka: Nauchno-prakticheskie aspekty(Cytogenetics of human embryonic development: Scientific and practical aspects) [in Russian]: SPb: Izdatel'stvo N-L; 2007: 640 p.

7. Spejcher MR, Antonarakis SE, Motulski AG. Genetika cheloveka po Fogeljui Motul'ski. Problemyi podhody (Human genetics according to Vogel and Motulsky. Problems and approaches) [in Russian]: SPb: Izdatel'stvo N-L; 2013: p.1056.

8. Kim K, Wang Y, Kirby RS, Druschel CM. Prevalence and trends of selected congenital malformations in New York State, 1983 to 2007. Birth defects research Part A.Clinical and molecular teratology. 2013; 97(10): 27-619. 